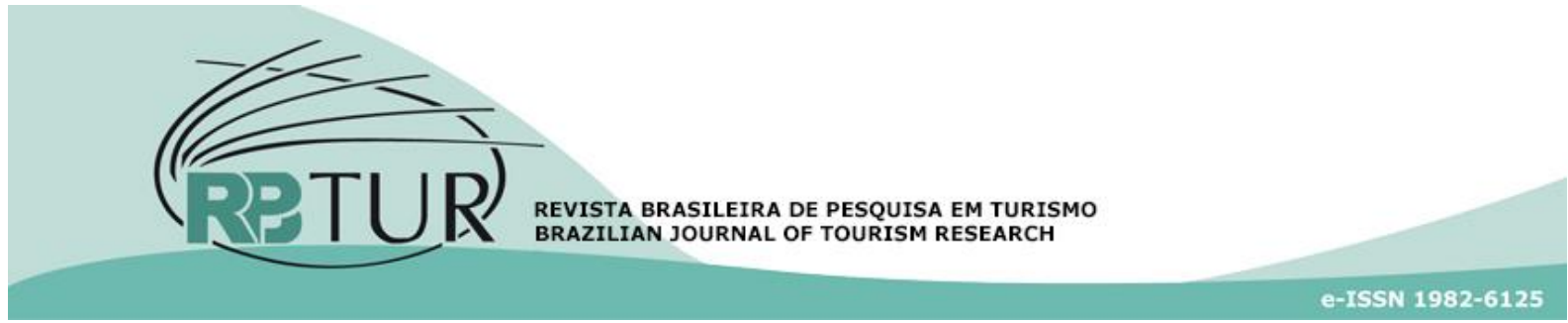

Artigos

DOI: http://dx.doi.org/10.7784/rbtur.v11i2.1237

\title{
Estudo sistêmico da paisagem no empreendimento turístico "Ilha de Porto Belo" em Santa Catarina, Brasil, na perspectiva de sua sustentabilidade
}

\author{
Systemic study of the landscape in the tourism enterprise "Ilha de \\ Porto Belo" in Santa Catarina, Brazil, from the perspective of its \\ sustainability
}

\section{Estudio sistémico del paisaje en el emprendimiento turístico "Isla de Porto Belo" en Santa Catarina, Brasil, desde el punto de vista de su sostenibilidad}

\section{Rafaela Vieira ${ }^{1}$ \\ Carolina Schmanech Mussi ${ }^{2}$ \\ Paulo dos Santos Pires ${ }^{3}$}

Resumo: O estudo teve como objetivo analisar os aspectos naturais da Ilha de Porto Belo em Santa Catarina, bem como sua relação com os atrativos do complexo turístico nela implantado. A justificativa aponta para a expectativa de uma contribuição metodológica e empírica, com a revelação das relações entre os recursos ecossistêmicos e os processos relacionados aos atrativos deste destino, sob o paradigma da sustentabilidade do turismo. No tocante à metodologia, a pesquisa foi do tipo descritiva, de caráter quali-quantitativo e amparada no método sistêmico de abordagem. Os procedimentos técnicos foram distribuídos em três etapas: levantamento de dados bibliográficos, documentais e de campo; mapeamento e cruzamento; síntese e resultado. O Sistema de Informação Geográficas (SIG) foi a ferramenta utilizada na identificação, dimensionamento e analise sistêmica das unidades da paisagem na ilha. A originalidade dos resultados consiste na hierarquização do sistema natural e social do ambiente a partir do mapeamento da estabilidade das unidades

\footnotetext{
${ }^{1}$ Universidade Regional de Blumenau (FURB), Blumenau, SC, Brasil. Formulação das ideias do trabalho científico, redação do trabalho, interpretação dos dados e revisão crítica.

2 Universidade do Vale do Itajaí (UNIVALI). Balneário Camboriú, SC, Brasil. Coleta e processamento dos dados, desenvolvimento metodológico, elaboração dos resultados e mapeamentos cartográficos.

3 Universidade do Vale do Itajaí (UNIVALI). Balneário Camboriú, SC, Brasil. Elaboração do referencial teórico, redação e revisão crítica do trabalho, preparação do artigo científico.
}

Artigo recebido em: 05/10/2016. Artig aprovado em: 17/03/2017.

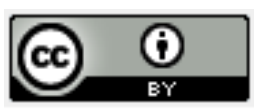


da paisagem, bem como na indicação dos espaços e infraestruturas que podem ser requalificadas para aprimorar os serviços na ilha. Este resultado agregado à discussão sobre o seu efeito prático para a gestão sustentável dos espaços de lazer e das atividades de recreação na llha, mostra-se original e contributivo, diante do estado da arte da produção científica do turismo no país.

Palavras-chave: Turismo. Sustentabilidade. Sistemas de Informações Geográficas (SIG). Unidades da Paisagem. Ilha de Porto Belo-SC.

Abstract: This study aims to analyze the natural environmental of the island of Porto Belo, in Santa Catarina, and its relationship with the tourism complex in the island. We expect to make a methodological and empirical contribution to research on tourism sustainability, as the findings suggest a relationship between the ecosystem and the processes related to the attractions of the destination. This is a descriptive study, using both qualitative and quantitative methodology, based on a systemic approach. The technical procedures were divided into three stages: literature, documentary, and field survey; mapping and crossing; summary and results. The Geographic Information System (GIS) was the instrument used in the identification, sizing and systemic analysis of landscape units of the island. The originality of this study lies in ranking the natural and social environment systems from the mapping of the stability of landscape units, as well as in the identification of spaces and infrastructures that can be requalified in order to improve the services on the island. This result and the discussion of its contribution to the sustainable management of leisure and recreation activities on the island are original contributions to the state-of-the art to tourism research Brazil.

Keywords: Tourism. Sustainability. Geographic Information Systems (GIS). Landscape Units. Ilha de Porto BeloSC.

Resumen: El objetivo del estudio fue analizar los aspectos naturales de la isla de Porto Belo en Santa Catarina, así como su relación con el complejo de los atractivos turísticos implantados en ella. La justificación apunta a la expectativa de un aporte metodológico y empírico para la revelación de las relaciones entre los recursos de los ecosistemas y los procesos relacionados con los atractivos de este destino, bajo el paradigma de la sostenibilidad del turismo. En cuanto a la metodología, la investigación fue descriptiva, con el enfoque cualitativo y cuantitativo y apoyada en el método sistémico de explicación. Los procedimientos técnicos se dividieron en tres etapas: recolección de datos bibliográficos, documentales y de campo; cartografía del campo y cruce de los datos; síntesis y resultado. El Sistema de Información Geográfica (GIS) fue la herramienta utilizada en la identificación, dimensión y análisis sistémico de las unidades de paisaje de la isla. La originalidad de los resultados se encuentra en la jerarquía del sistema natural y social del ambiente, hecha desde el mapeo de la estabilidad de las unidades de paisaje; así como en la indicación de los espacios de ocio y de las infraestructuras, que pueden ser recalificados para mejorar los servicios en la isla. Este resultado, agregado a la discusión de su efecto útil para la gestión sostenible de los espacios de ocio y las actividades recreativas de la isla, parece ser original y contributivo delante de la situación de la producción científica del turismo en el país.

Palabras clave: Turismo. Sostenibilidad. Sistemas de Informaciones Geográficas (SIG). Unidades de Paisaje. Isla de Porto Belo-SC.

\section{INTRODUÇÃO}

Em Santa Catarina, o circuito litorâneo atrai um fluxo cada vez maior de turistas, tendo em vista o apelo cênico de suas praias e a concentração dos serviços de apoio ao turismo. Com uma orla marítima de 561,4
$\mathrm{Km}$, o estado catarinense se afirma nacional e regionalmente como a rota de veraneio, apresentando indicadores favoráveis para que muitas localidades desenvolvam suas potencialidades por meio de iniciativas que visam a implementação e a consolidação de atividades turísticas. É assim que nas últimas décadas, seu desenvolvimento turístico no 
litoral Norte, polarizada por Balneário Camboriú, demonstrou um dinamismo que produziu mudanças e provocou impactos também sobre os balneários vizinhos, a exemplo de Porto Belo.

O turismo costeiro é baseado em uma combinação única de recursos entre a interface terra e mar, que oferece atrativos como a água, as praias, a biodiversidade terrestre e marinha, além de um rico patrimônio histórico e cultural, alimentação prazerosa e com infraestrutura básica para permanência e fruição do turista.

Por outro lado as zonas costeiras apresentam alta fragilidade ambiental, pois enfrentam diversas pressões antropogênicas devido à variedade de atividades econômicas e turísticas, necessitando de planejamento que garanta a sustentabilidade de seus bens e serviços ecossistêmicos (Alister, 1982; Santos, Melo \& Brito, 2013). Em particular, a vulnerabilidade das ilhas é decorrente das suas características peculiares, como a pequena extensão territorial, constituindo-se um fator econômica-social e ambientalmente limitante (Carvalho; Decol; Gil; Lanzer, 2016).

Segundo Ruschmann (2009) a natureza constitui o único fator do produto turístico que não pode ser ampliado, sendo a base da existência, atratividade e destaque turístico, necessitando cada vez mais de planejamento que minimize os impactos negativos do desenvolvimento econômico. Para Silva \& Cândido (2016), o turismo constitui-se em uma atividade econômica com potencial para o desenvolvimento local, sendo necessário refletir sobre os impactos ambientais, sociais, econômicos e culturais, para o alcance dos princípios da sustentabili- dade.

Remetendo ao objeto específico deste estudo, no alto verão da temporada 1996-1997 foram inaugurados os equipamentos turístico-recreativo na Ilha João da Cunha, mais conhecida como llha de Porto Belo, localizada na costa do município homônimo, estimulando a iniciativa de uma equipe multidisciplinar constituída por docentes e acadêmicos do Curso de Graduação e do Programa de Mestrado em Turismo e Hotelaria da Universidade do Vale do Itajaí - SC, a desenvolver estudos específicos no sentido de observar a visitação a Ilha, estudar os impactos ambientais e definir a capacidade de carga turística.

Assim, como atestam Ruschmann; Rosa e Weidgenant (2010, p. 813), desenvolveu-se o projeto para implantação do Empreendimento Ilha de Porto Belo por meio da concepção da exploração turística sustentável, preservando a natureza, harmonizando a construção de equipamentos e controlando o fluxo turístico. $\mathrm{Na}$ mesma linha, Oliveira et al. (2016), afirmam no turismo e hotelaria, a sustentabilidade deve ser objetivo da equipe de gestão, incorporando-se elementos naturais relativos à localidade onde o empreendimento se insere, proporcionando maior durabilidade e menor custo, sendo muitas vezes fator decisivo na escolha por determinado empreendimento.

Desde então, ao longo das temporadas subsequentes foram se replicando os estudos geradores de conhecimento para a academia e de subsídios para os gestores do empreendimento turístico recreativo em 
funcionamento na llha. É esta cultura de trabalhos e investigações acadêmicas que ensejou mais recentemente a ampliação das abordagens. Dessa forma, este estudo teve por objetivo analisar os aspectos naturais e sua relação com os atrativos turísticorecreativos da Iha de Porto Belo, com base no estudo sistêmico das unidades da paisagem. Para tanto, o trabalho identifica, dimensiona e analisa de forma sistêmica as unidades da paisagem na ilha por meio de Sistemas de Informações Geográficas (SIG) a fim de compreender os processos turísticos e ambientais, permitindo a identificação dos espaços, infraestruturas e serviços que podem ser aprimorados, consolidando sua sustentabilidade turística.

Trata-se de um estudo com viés, sobretudo, metodológico, amparado pelo método sistêmico de abordagem. Enfatiza o desenho e a aplicação de procedimentos quali-quantitativos, cujos resultados resultam em mapeamentos da estabilidade das unidades da paisagem. Portanto, a discussão gerada se dá sobre o efeito prático da geração e disponibilização destas informações para a gestão sustentável dos espaços de lazer e das atividades de recreação na llha.

O estudo se insere no âmbito de um projeto de pesquisa mais amplo intitulado " $\mathrm{A}$ Ilha de Porto Belo-SC como Modelo de Gestão do Uso Turístico-Recreativo para a Sustentabilidade Ambiental de Destinos Insulares no Brasil" aprovado e financiado pelo Conselho Nacional de Desenvolvimento Científico e Tecnológico - CNPq, através da Chamada Universal MCTI/CNPq no 14/2013.

A seguir, apresenta-se a abordagem teórica do estudo, o percurso metodológico adotado, apresentação dos resultados e respectivas discussões e as considerações finais.

\section{ABORDAGEM TEÓRICA DO ESTUDO}

\subsection{A sustentabilidade ambiental do turismo no contexto costeiro}

O planejamento do turismo consiste em ordenar as ações do homem sobre o território e ocupa-se em direcionar a construção de equipamentos e facilidades de forma adequada, a fim de evitar os efeitos negativos que destroem os recursos ou reduzem a sua atratividade (Ruschmann, 2009). Assim é possível gerenciar o desenvolvimento turístico visando minimizar impactos negativos e estimular os impactos positivos Cooper (2001). Para Costa e Miranda (2016) há necessidade de planejamento do turismo para que os danos causados aos locais de visitação sejam mínimos.

Nesta perspectiva, apesar do desgaste e da banalização de sua apropriação generalizada e inconsequente por muitos agentes públicos e privados da sociedade, o paradigma da sustentabilidade não deixou de ser o marco universal capaz de contextualizar teórica e empiricamente a relação entre o método de análise sistêmico e o objeto real desse estudo, uma pequena ilha onde há quase 20 anos vem se desenvolvendo uma experiência exitosa de uso turísticorecreativo de seus espaços naturais.

Buckley (2012) considera que a sustentabilidade é tão importante e igualmente 
difícil de alcançar, tanto no turismo como em qualquer outro setor de economia humana. Torres-Delgado e Palomeque (2012) ponderam sobre o carácter impreciso da sustentabilidade, $\mathrm{o}$ qual se reflete no conceito de turismo sustentável, favorecendo assim o seu uso retórico, o que leva a múltiplas interpretações e, consequentemente, a aplicações com intensidade e finalidades variável. Para Jovicic (2014) o uso generalizado do termo "turismo sustentável" gera polêmica e confrontos quanto à sua interpretação e as possibilidades de implementação prática de seu conceito. Além disso, a realização da satisfação de todas as partes interessadas é uma questão chave e difícil de ser alcançada. De forma convergente, Ruhanen (2008) fala da diferença entre a teoria e a prática marcada pela facilidade em se fazer proselitismo sobre o tema a despeito do desafio de seu processo prático, o que na observação de Bramwell (2015) faz do turismo sustentável objeto de críticas em relação à extensão de sua aplicação e eficácia.

Neste sentido, Jiménez e Nechar (2014) observam que não é uma tarefa fácil combinar todos os elementos da operação turística com a sustentabilidade. Para tanto é necessário ter uma clareza sobre os conceitos e metodologias que embasam a sustentabilidade do destino.

Apesar dessas limitações, a sustentabilidade é amplamente aceita como uma característica desejável do turismo contemporâneo e deve ser considerada como um fator crítico em qualquer iniciativa que exerça influência no turismo (Torres-
Delgado \& Palomeque, 2012). Contudo, a constatação de que é possível desenvolver um turismo não massivo e ao mesmo tempo viável para o destino, como no caso do objeto deste estudo que é a llha de Porto Belo no Estado de Santa Catarina/Brasil, encontra respaldo do principal organismo global para a governança do turismo, que é a Organização Mundial do Turismo (OMT). A atuação da OMT desde os anos 1990 e de forma mais intensa a partir dos anos 2000 , tem resultado na difusão de importantes documentos de referência, com base empírica para a sustentabilidade do turismo.

Assim, podem ser destacados os indicadores de desenvolvimento sustentável para destinos turísticos (WTO, 2004), um guia centrado no uso de indicadores como instrumento para auxiliar os gestores de empresas e destinos para melhorar o planejamento e a gestão do turismo. Em um total de 18 tipos de destinos, apenas para os destinos de praias, são aproximadamente 50 indicadores de sustentabilidade. Nesta mesma linha, o Global Sustainable Council Tourism Criteria for Destinations (GSTC, 2008), um conselho mundial que cria e gere padrões globais de sustentabilidade, estabeleceu 41 critérios, com seus respectivos indicadores, distribuídos em quatro temas principais relacionados à cultura, ambiente, economia e gestão do destino.

Tanto a OMT quanto o GSTC esclarecem que diante das diferenças e especificidades de cada destino, há que se adequar e selecionar os respectivos critérios/indicadores a serem efetivamente adotados para o planejamento e a gestão do 
turismo na perspectiva de sua sustentabilidade. Enfim, trata-se de uma preocupação que remonta aos anos 1990, em que Butler (1991), já apresentava indicadores de sustentabilidade para o setor do turismo.

Não obstante todo este esforço institucional para a gestão da sustentabilidade e a sua implementação em alguns destinos turísticos, para Buckley (2012) é evidente que o turismo, assim como qualquer outro setor da economia como um todo, está longe de ser plenamente sustentável. Com exceção de algumas empresas específicas, a atividade turística se concentra fortemente nos aspectos econômicos, sendo que os aspectos sociais e ambientais se restringem a atender às conformidades legais e estratégias políticas de marketing e de relações públicas.

No âmbito da governança, o Programa das Nações Unidas para o Meio Ambiente (PNUMA) em conjunto com a OMT publicaram um manual de consulta para que os governos ou agentes públicos adotem abordagens eficazes e elaborem estratégias e políticas para tornar o turismo mais sustentável (WTO, 2005). Já a relação entre a sustentabilidade com as normas e sistemas qualidade do turismo e sua situação na região das Américas, foi objeto de outra publicação da OMT (WTO, 2010). Em outro documento deste organismo mundial (WTO, 2013a), aborda-se a situação do turismo nos pequenos estados insulares em desenvolvimento e oferecem orientações e diretrizes para que os agentes do turismo nestes países desenvolvam e gestionem o turismo de uma forma sustentável em benefício de suas populações.
Já a gestão do turismo em zonas costeiras mereceu um outro estudo da OMT também recente (WTO, 2013b), pelo qual são identificados e avaliados os instrumentos políticos que influenciam na sustentabilidade do turismo nestas áreas buscando, entre outros objetivos, a conservação da biodiversidade e $o$ bem estar das comunidades locais. Por fim, mesmo quando se trata de orientar para aspectos puramente de gestão, de profissionalização e de qualidade no destino, nas organizações e no produto turístico, há documentos de referência mundialmente difundidos com esta finalidade (WTO, 2007; 2011). Outras organizações internacionais, instituições acadêmicas, governos e empresas privadas, de acordo com (Blancas et al., 2010), vêm buscando definir sistemas de indicadores a fim de avaliar a efetividade do turismo sustentável em diferentes destinos.

Enquanto as organizações globais tentam cumprir este seu papel de balizadoras do desenvolvimento sustentável do turismo, para esta mesma finalidade se estabelecem desafios no plano real em outras frentes. Neste sentido, Williams e Ponsford (2009) constatam que as agências reguladoras ao desenvolveram diretrizes para as melhores práticas de gestão ambiental, convivem com situações como: incerteza de como tais iniciativas serão recebidas pelos fornecedores do turismo e seus clientes; pouco interesse dos governos em sobrecarregar as empresas de turismo com novos regulamentos que possam desestimulá-las a continuar gerando receitas em impostos; adoção das práticas de sustentabilidade costuma ser lenta devido à 
falta de liderança e de responsabilidades compartilhadas entre os agentes do turismo. Contudo, como enfatizam Rosa \& Silva (2017), a sustentabilidade particularmente na sua dimensão ambiental, é um tema relevante e atual, conforme se constata em estudos tanto na esfera organizacional, quanto na econômica e na política.

De acordo com Pearce (2016), para se assegurar que os destinos turísticos sejam sustentáveis e competitivos, identifica-se tanto na prática como em pesquisas científicas a existência de uma variedade de modelos de gestão do destino turístico. Dessa forma, é fundamental que se reconheça essa diversidade, visto que nenhum modelo é completo, pois cada um tem seus pontos fortes e suas limitações.

\subsection{A qualificação dos destinos e a abordagem sistêmica da paisagem}

Os viajantes enquanto consumidores podem exercer um poder significativo para a formatação de produtos "verdes", levando os operadores do turismo a satisfazer a sua emergente sensibilidade ambiental. $\mathrm{O}$ equilíbrio, a longo prazo, entre o uso apropriado ou excessivo dos recursos ambientais de um destino e a manutenção de sua atratividade para a demanda é uma questão fundamental (Williams \& Ponsford, 2009).

O turismo deve manter um elevado nível de satisfação e garantir uma experiência significativa para os turistas que querem encontrar ambientes limpos, recursos naturais atraentes e pessoas acolhedoras nos destinos, entre outras motivações OMT
(2003). Com isso, a preocupação com a qualidade do destino é essencial para o sucesso na atividade turística, já que as emoções dos visitantes estão intrinsecamente relacionadas à satisfação e superação de suas expectativas (Ruschmann, Rosa \& Weidgenant, 2008). Segundo Boullón (2002), a imagem de um lugar turístico deve levar em consideração o programa de atividades e a qualidade do atrativo, seja natural ou urbano. Esta imagem é um aspecto primordial do sucesso e da imagem de uma destinação turística (Sancho, 2001).

Numa visão mercadológica da sustentabilidade do desenvolvimento turístico, de acordo com Moraes (2012, p. 284), se sobressaem os destinos capazes de oferecer vantagens comparativas que são provenientes das características originais da localidade, no caso da IPB, o notável nível de integridade fisiográfica de seus elementos naturais, e as vantagens competitivas, que no mesmo caso, consistem na forma como estão sendo trabalhadas estas características originais a fim de proporcionar uma experiência turística diferenciada aos visitantes. Para o PNUMA \& OMT (2006), grande parte do setor turístico é dependente de ambientes intactos e limpos, recursos naturais atraentes, tradições históricas e culturais autênticas e pessoas acolhedoras nos destinos, que é o que os visitantes buscam encontrar.

Portanto o planejamento das ações para a qualificação de empreendimentos turísticos em ambientes naturais deve considerar a produção de infraestrutura, equipamentos e serviços para o turista (Ribeiro e Stigliano, 2010). Para tanto é 
importante compreender o ambiente e os processos que ocorrem nos espaços turísticos de forma sistêmica, na medida em que a imagem destes ambientes está condicionada as relações entre natureza e sociedade.

A abordagem sistêmica está ligada à noção de vários elementos em contínua interação, cujo comportamento não é linear (Bertalanffy, 2009). Somos forçados a tratar com complexos, com 'totalidades' ou 'sistemas' em todos os campos de conhecimento. Capra (1992) corrobora com a importância da visão sistêmica nos diversos campos científicos, afirmando que os modelos lineares não são suficientes.

A interpretação do comportamento ambiental a partir de uma visão sistêmica admite que a ideia de que o todo não se constitui pela soma das partes, mas por processos complexos que envolvem a compreensão tanto da organização (estrutura), como do funcionamento (processo) do objeto de estudo (Drack \& Bertalanffy, 2008).

Com base na abordagem sistêmica, a compreensão do ambiente pode se dar por meio da paisagem, enquanto um conceitochave, um instrumento integrador dos aspectos naturais e sociais. A paisagem pode ser definida como uma unidade espacial percebida ou sentida, resultante da combinação heterogênea de elementos bióticos, abióticos e socioeconômicos em diferentes escalas espaços-temporais. É um estudo da estrutura, função e dinâmica de áreas heterogêneas compostas por ecossistemas interativos (Formam \& Gordon, 1986). Segundo Odum \& Barrett (2011) a paisagem engloba pessoas e natureza servindo como um instrumento fundamental para estudos integrados do meio.

Neste estudo, a paisagem é entendida enquanto um conceito-chave para compreensão integrada do ambiente que se configura em um sistema complexo. Ou seja, a paisagem não existe por si mesma, mas é uma abstração para o estudo do ambiente, composta pela articulação de elementos naturais e edificados.

Para Tres, Reis \& Schlindwein (2011) a paisagem resulta da presença do homem ao interferir no ambiente, criando novas situações e exigindo cada vez mais recursos naturais, o que gera impactos geralmente negativos. Expressa como uma unidade complexa e com elementos interdependentes e interativos, a paisagem constitui-se no resultado da interação da sociedade humana com seu espaço de vida, natural e construído.

Adotou-se a paisagem como uma unidade ambiental que vai além dos aspectos meramente formais, buscando compreender sua função, estrutura e processo. Para tanto, apropria-se das categorias "forma, função, estrutura e processo" propostas por Santos (1992), para a análise do espaço, as quais entende-se que podem ser utilizadas também no estudo da paisagem. Assim, segundo o referido autor, o espaço constitui uma realidade objetiva em permanente processo de transformação, e para estudá-lo deve-se apreender sua relação com os processos produtivos sociais, no decorrer do tempo. Já a paisagem é o resultado cumulativo desses tempos nos níveis regional e local, sendo formada pelos fatos do passado e do presente. Corroborando essa 
ideia Oliveira (1999) afirma que a paisagem é o resultado de processos naturais e das ações antrópicas, constituindo-se na materialização das ações humanas e/ou de processos naturais ocorridos em uma determinada área no decorrer do tempo. Yázigi (2003) associa a paisagem à passagem do tempo sobre um determinado local.

Para Figueiró (1997) a definição de paisagem como algo dinâmico e complexo, além do seu caráter fisionômico (forma, aparência), é uma criação da modernidade, no século XIX. Para Bertrand (1972, p.2), os elementos que constituem a paisagem participam de uma dinâmica comum, a qual não corresponde à evolução específica de cada elemento:

A paisagem não é simples adição de elementos geográficos disparatados. É numa determinada porção do espaço, o resultado da combinação dinâmica, portanto instável, de elementos físicos, biológicos e antrópicos que, reagindo dialeticamente uns sobre os outros, fazem da paisagem um conjunto único $e$ indissociável, em perpétua evolução. (Ibid)

Assim, a delimitação da paisagem não é um fim em si, mas um meio de aproximação com a realidade. Não se dá pela simples sobreposição de elementos, mas pelas suas relações, articulações, por ser entendida enquanto um instrumento para o estudo do ambiente.

Unidades de paisagem podem ser entendidas como sistemas que guardam relativa homogeneidade em relação a sua composição formal e funcional, bem como de sua organização (estrutura e processo) e dinâmica (Bertalanffy, 2009). O estudo das unidades da paisagem tornou-se uma ferramenta importante para o manejo da natureza em beneficio da sociedade (Odum \& Barrett, 2011), servindo como unidade espacial para análise sistêmica. Os Sistemas de Informações Geográficas surgem como uma ferramenta que permite o cruzamento dos dados físicos e sociais de forma precisa e automatizada, gerando mapeamentos temáticos que facilitam a compreensão de processos e estruturas complexas.

\section{PERCURSO METODOLÓGICO}

O destino turístico llha de Porto Belo IPB, pertencente ao município de Porto Belo no litoral centro norte de Santa Catarina, com coordenadas geográficas $27^{\circ} 08^{\prime} 13^{\prime \prime} \mathrm{de}$ latitude Sul e $48^{\circ} 32^{\prime} 17^{\prime \prime}$ de longitude Oeste (Figura 1). 
Figura 1 - Localização geográfica da Ilha de Porto Belo no Litoral Centro Norte de SC
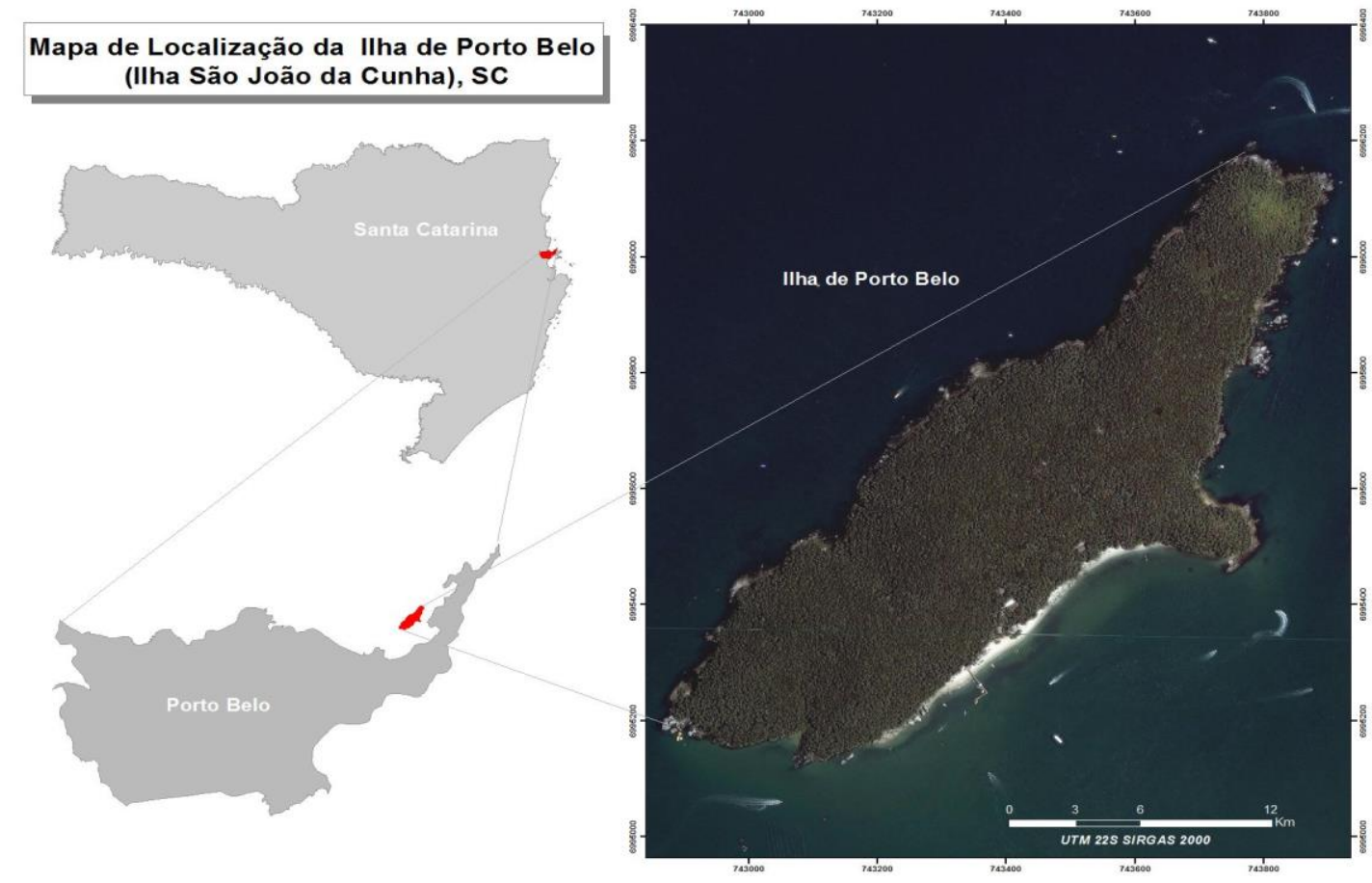

Fonte: Elaboração própria

Distante $25 \mathrm{Km}$ da cidade de Balneário Camboriú e $64 \mathrm{Km}$ da capital do Estado, a IPB possui uma área aproximada de 40 hectares, com cobertura vegetal natural de Mata Atlântica secundária e sua distância do continente é de apenas 900 metros. O projeto arquitetônico dos equipamentos colocados à disposição dos visitantes foi desenvolvido por meio da concepção da exploração turística sustentável, com a construção de equipamentos turísticos em harmonização com o meio físico e o controle do fluxo turístico visando, justamente, a proteção e valorização da natureza cuja ocorrência é notável na Ilha.

Nesta pesquisa, as técnicas incluíram a pesquisa bibliográfica e documental além de levantamentos a campo. O estudo foi dividido em três etapas: (1) levantamento de dados; (2) mapeamento e cruzamento; (3) síntese e resultado.
A primeira etapa consistiu no levanmento de dados secundários e primários por meio de pesquisa documental e de campo, respectivamente. Os dados secundários utilizados para caracterização dos sistemas naturais foram disponibilizados pela empresa Socioambiental Consultores Associados (EIA, 2008), incluindo a caracterização da geomorfologia, hipsometria, cursos de água intermitentes e cobertura vegetal. A caracterização do sistema social foi realizada em campo com observação visual para obtenção dos dados primários. 0 dimensionamento das unidades de paisagem foi realizado através de levantamento geodésico com o sistema DGPS (RTK - Real Time Kinematic) modelo TRIMBLE R6.

O levantamento geodésico, que registrou 508 pontos, foi realizado em duas saídas de campo nos dias 16 e 23 de abril de 2014, incluindo a demarcação da área de 
banho, praias, áreas de circulação, passarelas, trilhas, piers, tiroleza, mirantes e edificações. O levantamento da área das praias foi realizado nos períodos de maré de quadratura em seu estado vazante, e portanto, com a maior extensão possível de praia. (Figura 2). As áreas dos levantamentos foram calculadas utilizando a ferramenta Calculate Geometry do ArcGIS 10.0.

As variáveis utilizadas para caracterizar as unidades de paisagem para análise sistêmica estão descritas no Quadro 1.

\begin{tabular}{|c|c|c|}
\hline $\begin{array}{c}\text { SISTEMA NATURAL } \\
\text { Variáveis }\end{array}$ & $\begin{array}{l}\text { CATEGORIAS } \\
\text { ANALÍTICAS }\end{array}$ & $\begin{array}{l}\text { SISTEMA SOCIAL } \\
\text { Variáveis }\end{array}$ \\
\hline $\begin{array}{c}\text { Geomorfologia } \\
\text { Hipsometria } \\
\text { Cursos de água intermitentes } \\
\text { Cobertura vegetal }\end{array}$ & FORMA & $\begin{array}{c}\text { Atrativos Naturais: como praias; costões } \\
\text { inscrições rupestres, entre outros } \\
\text { Atrativos Construídos: restaurante; quiosques, } \\
\text { entre outros } \\
\text { Infraestrutura: passarelas, banheiros, etc }\end{array}$ \\
\hline Proteção ambiental & FUNÇÃO & Turística \\
\hline $\begin{array}{c}\text { Matriz de relacionamento } \\
\text { natural } x \text { social }\end{array}$ & ESTRUTURA & Matriz de relacionamento natural x social \\
\hline $\begin{array}{l}\text { constante/transição/ } \\
\text { inconstante }\end{array}$ & PROCESSO & constante/transição/inconstante \\
\hline
\end{tabular}

Fonte: Adaptado de Santana (1998) e Vieira (1999)

A segunda etapa contou com o mapeamento e cruzamento das variáveis que compõem o sistema natural e social, por meio do uso do software ArcGIS 10.0. A estabilidade das unidades da paisagem foi classificada em constante/transição ou inconstante a partir da interpretação de seu comportamento ambiental e sua adaptação aos princípios da sustentabilidade do turismo. No sistema natural considerou-se a suscetibilidade a movimentos gravitacionais de massa e no sistema social o dimensionamento da infraestrutura construída e sua freqüência de utilização pelos turistas.

Conforme metodologia de Crepani et al. (2001), adaptada por Tres; Reis e Schlindwein (2011) as variáveis utilizadas para caracterização da estabilidade das unidades da paisagem foram padronizadas através de uma hierarquização, nas quais as variáveis com valor 1 (um) foram classificadas como constante e adequadas à sustentabilidade do turismo, as variáveis com valor 2 (dois) foram classificadas como transição e aquelas com valor 3 (três) foram classificadas como inconstantes, constituindo-se em unidade da paisagem com instabilidade ambiental, pouco utilizada pelo turista ou sem espaço físico qualificado.

A classe de estabilidade do sistema social foi definida através de conhecimento empírico da área e a análise da frequência da utilização dos equipamentos de uso turístico baseou-se no estudo de Lessa (2006). Os atrativos com fluxo alto ou intenso foram considerados inconstantes à sustentabilidade 
do turismo, assim como os atrativos pouco utilizados pelos turistas, pois demonstram a baixa atratividade turística. A frequência de utilização dos espaços não citados por Lessa (2006) foram definidos a partir de observação visual durante as atividades de campo na ilha (Quadro 2).
O Quadro 3 mostra a classificação hierárquica das variáveis utilizadas para descrever a estabilidade das unidades da paisagem dos sistemas natural e social.

Quadro 2 - Frequência de utilização os espaços turístico-recreativos do complexo da IPB

\begin{tabular}{|c|c|c|}
\hline $\begin{array}{c}\text { Áreas inconstantes pouco } \\
\text { utilizadas pelos turistas / } \\
\text { demandam valorização do } \\
\text { espaço }\end{array}$ & $\begin{array}{l}\text { Áreas transição - áreas de } \\
\text { circulação mediana de } \\
\text { turistas }\end{array}$ & $\begin{array}{l}\text { Áreas constantes - áreas mais } \\
\text { frequentadas pelos turistas }\end{array}$ \\
\hline $\begin{array}{c}\text { Praias } \\
\text { Parquinho } \\
\text { Loja } \\
\text { Palco de Atividades } \\
\text { Cozinha } \\
\text { Mirante } \\
\text { Trapiche }\end{array}$ & $\begin{array}{c}\text { Quiosque tropical } \\
\text { Museu } \\
\text { Trilha ecológica } \\
\text { Restaurante central } \\
\text { Quiosque natural } \\
\text { Guarda volume - cadeiras } \\
\text { Restaurante } 4 \text { rodas } \\
\text { Quiosque tatto } \\
\text { Áreas circulação praia } \\
\text { Áreas banho navegação } \\
\text { Casa de máquinas } \\
\text { Tiroleza }\end{array}$ & $\begin{array}{c}\text { Passarelas } \\
\text { Quiosque náutico } \\
\text { Quiosque sucos } \\
\text { Sanitários } 1 \\
\text { Sanitários } 2 \\
\text { Quiosque informação } \\
\text { Escritório } \\
\text { ETE } \\
\text { Ambulatório } \\
\text { Trapiche inscrições rupestres }\end{array}$ \\
\hline
\end{tabular}

Fonte: Autoria própria

Quadro 3 - Classes da estabilidade das variáveis que descrevem as unidades da paisagem

\begin{tabular}{|c|c|c|c|}
\hline Estabilidade & Constante $=1$ & Transição = 2 & Inconstante = 3 \\
\hline \multicolumn{4}{|c|}{ Variáveis Naturais } \\
\hline Vegetação & Estágio Avançado Regeneração & $\begin{array}{l}\text { Estágio Médio } \\
\text { Regeneração }\end{array}$ & $\begin{array}{c}\text { Estágio Inicial } \\
\text { Regeneração/Bambuzal }\end{array}$ \\
\hline Geologia & $\begin{array}{l}\text { Embasamento Cristalino } \\
\text { (Granito/Gnaise, Costão) }\end{array}$ & $\begin{array}{c}\text { Depósito } \\
\text { Eólico/Praial }\end{array}$ & $\begin{array}{c}\text { Depósito Coluvio- } \\
\text { Aluvional }\end{array}$ \\
\hline Declividade & $0-17^{\circ}$ & $17-45^{\circ}$ & $>45^{\circ}$ \\
\hline APP & Sem APP & --------- & Com APP \\
\hline Hipsometria & $0-5 m$ & $5,1-15 m$ & $>15 m$ \\
\hline \multicolumn{4}{|c|}{ Variáveis Sociais } \\
\hline $\begin{array}{l}\text { Dimensão } \\
\text { Estrutura }\end{array}$ & $\begin{array}{c}\text { Atrativos Naturais, Elementos Lineares } \\
\text { (trilhas) e }<50 \mathrm{~m}^{2}\end{array}$ & $50,1-160 m^{2}$ & $>160 \mathrm{~m}^{2}$ \\
\hline $\begin{array}{l}\text { Frequência } \\
\text { usuários }\end{array}$ & Fluxo de turistas adequado & $\begin{array}{l}\text { Fluxo de turistas } \\
\text { moderado }\end{array}$ & $\begin{array}{l}\text { Fluxo de turistas muito } \\
\text { baixo ou intenso }\end{array}$ \\
\hline
\end{tabular}

Fonte: Autoria própria 
A análise sistêmica se deu a partir do cruzamento das variáveis e hierarquização da estabilidade das unidades da paisagem por média aritmética de forma separada para os sistemas naturais e sociais, e a integração dos cenários se deu através da matriz de relacionamento indicada no Quadro 4.

Quadro 4 - Matriz de relacionamento pra definição da estabilidade de unidades de paisagem

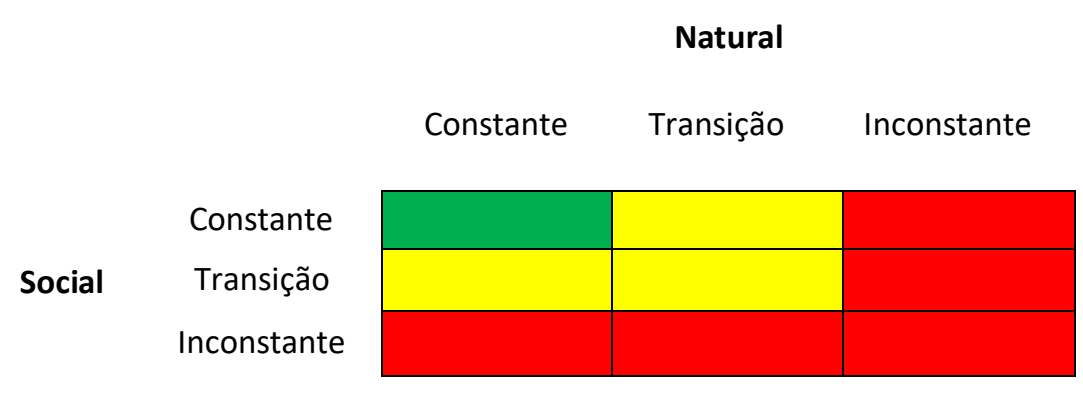

Fonte: Autoria própria

A terceira e última etapa da pesquisa é apresentada a seguir, constituindo-se em sua síntese e resultados obtidos.

\section{RESULTADOS E DISCUSSÃO}

Para caracterizar o sistema natural foram elaboradas as cartas temáticas de vegetação, geomorfologia, hidrografia, áreas de preservação permanente e declividade que constam no Relatório Técnico original da pesquisa.

A vegetação em estágio avançado de regeneração é predominante na Ilha de Porto Belo, conferindo-lhe uma paisagem natural exuberante, reforçando sua atratividade turística. Com relação à sua formação geomorfológica, predomina o embasamento cristalino, cuja estabilidade aos movimentos gravitacionais de massa é maior se comparado aos depósitos colúvioaluvionares, presentes em pequenos trechos distribuídos na ilha, junto aos cursos d'água. As margens desses corpos d'água e suas nascentes constituem-se em Áreas de Preservação Permanente (APP), segundo o código florestal, lei federal no. 12.651/2012. A essas APPs somam-se as declividades superiores a $100 \%$. Contudo, em função de algumas construções de uso turístico, nem todas essas áreas estão sendo preservadas.

A hierarquização das classes de estabilidade dos elementos da paisagem resultou inicialmente nos mapas temáticos dos sistemas naturais e sociais, respectivamente Figuras 3 e 4 . No mapa da estabilidade do sistema natural (Figura 2) percebe-se que grande parte da ilha foi apontada como área de transição, resultado de sua topografia acentuada. Entretanto, a maior parte destes espaços não é acessível ao turista.

As paisagens naturais próximas a linha de costa, onde ocorre o acesso ao 
turista, foram marcados por unidades da paisagem constantes. Nota-se a existência de poucas unidades da paisagem classificadas como inconstantes e correspondem às Áreas de Preservação Permanente sob influência dos canais de drenagem superficial. Estas indicam áreas suscetíveis a movimentos gravitacionais de massa. Pontualmente correspondem as áreas próximas ao museu e em porções da trilha que dá acesso ao mirante e ao sítio arqueológico.

Figura 2 - Estabilidade dos elementos naturais das unidades da paisagem

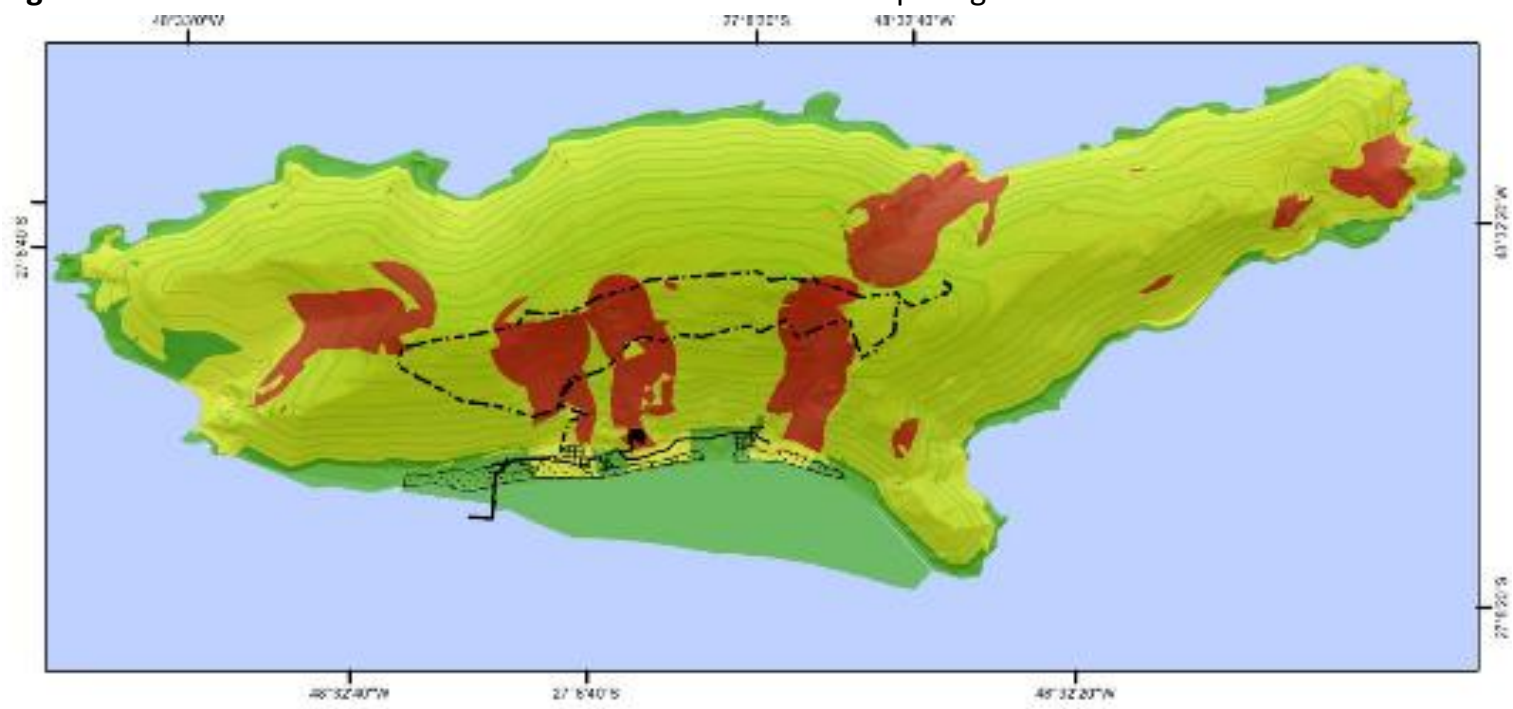

Estabilidade Elementos Naturais das Unidades da Paisagem da liha de Porto Belo- SC
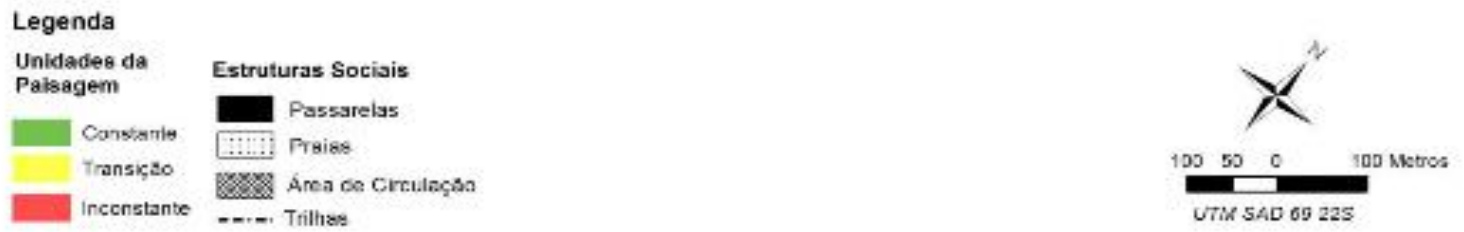

Fonte: autoria própria

A estabilidade do sistema social com base na dimensão da edificação e na frequência de turistas em cada atrativo/infraestrutura da ilha (Lessa, 2006) está apresentada na Figura 3. No sistema social grande parte da paisagem foi classificada como estável. As áreas de circulação, náutica e de banho, as praias e trilhas que foram classificadas como transição. Também as edificações do quiosque náutico, ambulatório, banheiros da segunda praia e os quiosques - petiscos, sucos, drinques e informações foram classificados como transição. Como unidades da paisagem inconstantes estão: o mirante, o píer de chegada, a casa de máquinas, loja de suvenires, o palco de atividades, o parquinho, o museu, o restaurante central e o da segunda praia. 
Figura 3 - Estabilidade dos elementos sociais das unidades da paisagem
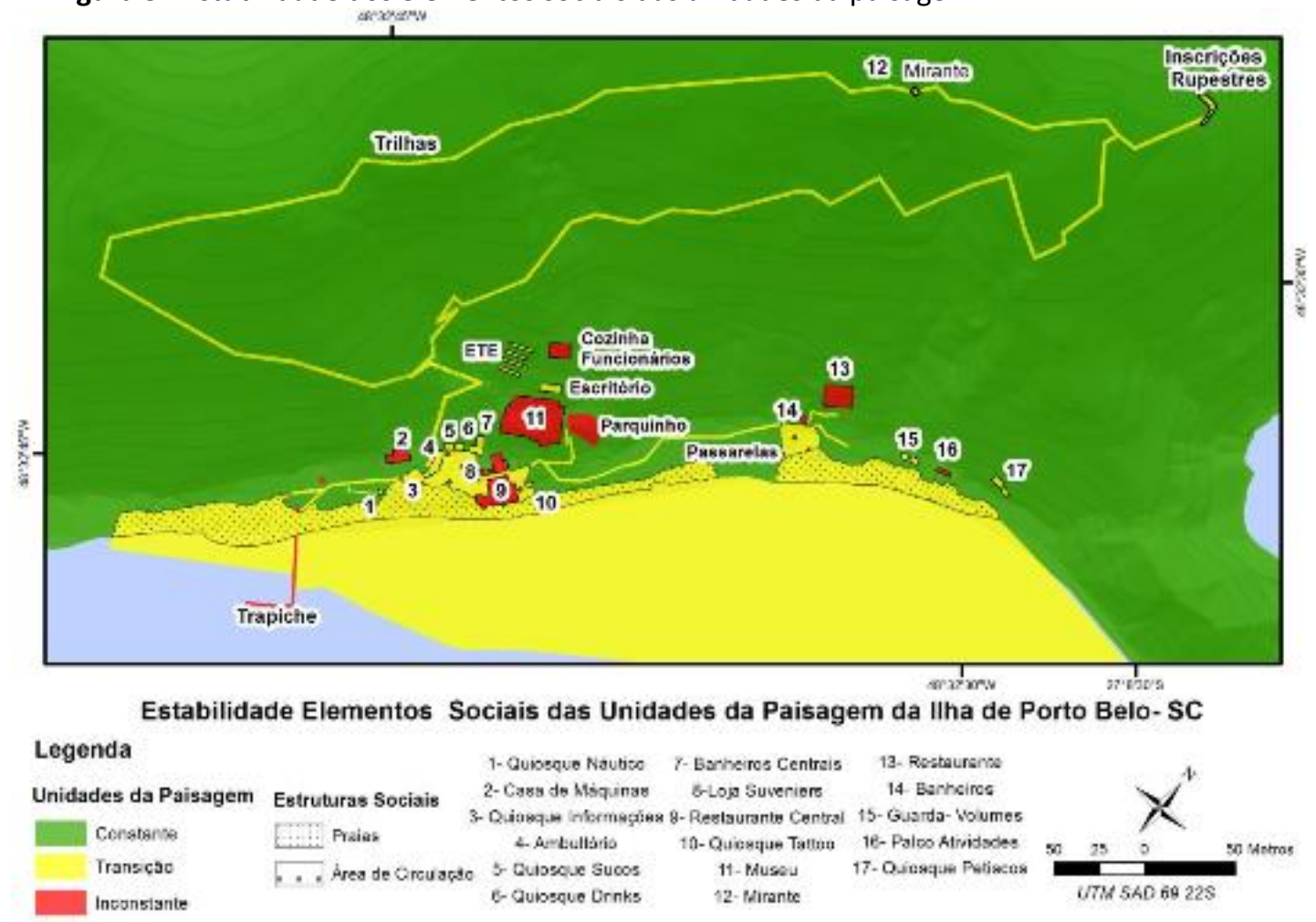

Fonte: autoria própria

Na integração dos cenários do sistema natural e social, ou seja, por meio do cruzamento deles na matriz de relacionamento (Figura 4), as unidades da paisagem inconstantes aumentaram. Contudo, nos espaços em que o turista tem acesso houve pouca alteração da estabilidade. A integração dos cenários apontou as seguintes unidades da paisagem como inconstantes: museu, parquinho, píer chegada, casa de máquinas, restaurante central e da segunda praia, mirante, algumas porções da trilha, aloja de suvenires e o palco.

Com base na análise sistêmica realizou-se estudo sobre o estabilidade da paisagem em relação à sustentabilidade do turismo na llha de Porto Belo, tendo-se identificado a estabilidade das unidades da paisagem como constante, transição ou inconstante. 
Figura 4 - Estabilidade das unidades da paisagem da área de acesso da Ilha de Porto Belo-SC

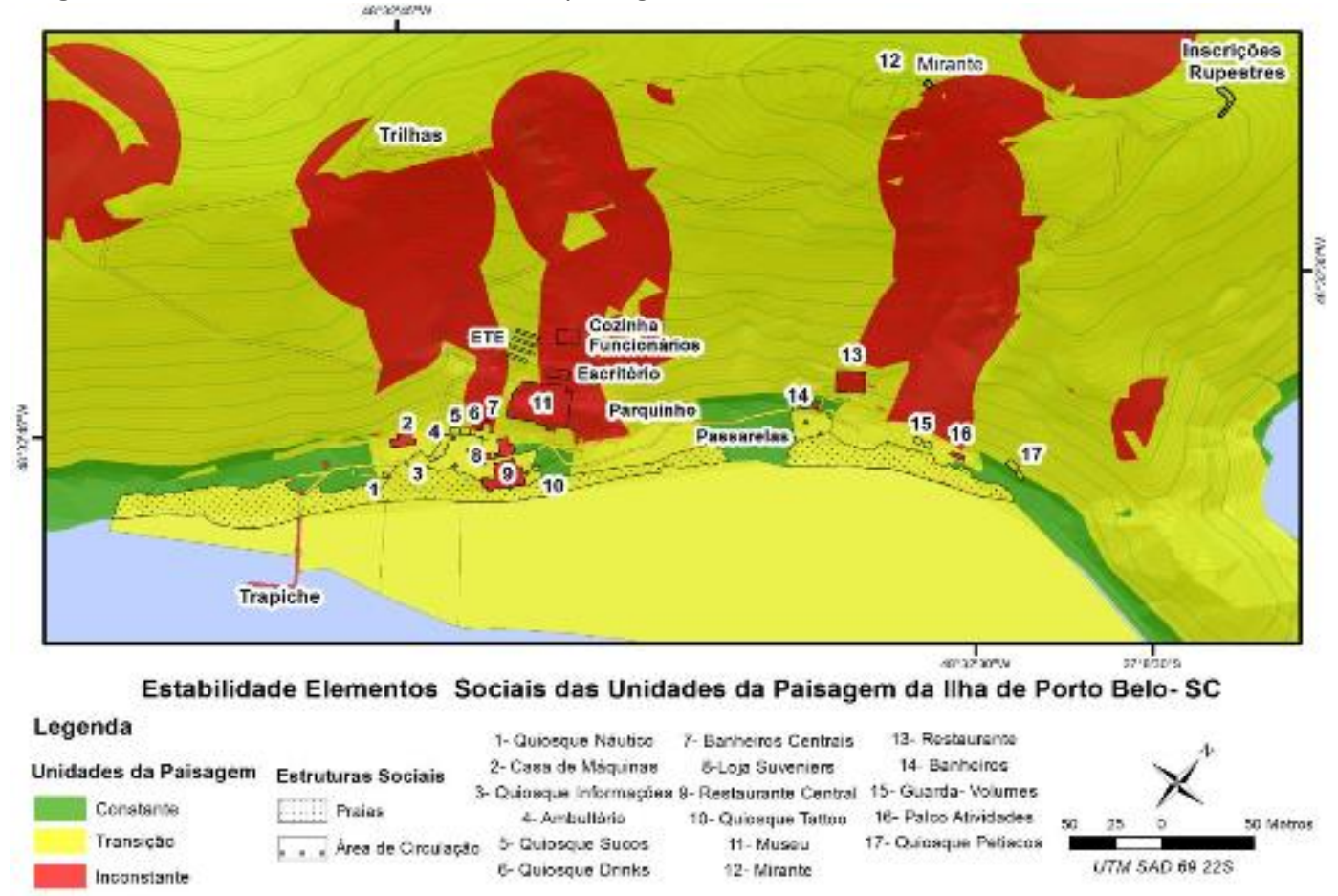

Fonte: autoria própria

Cabe destacar que as áreas de praia merecem atenção, mesmo tendo sido classificadas como unidade da paisagem de transição. $\mathrm{A}$ área da praia mensurada nesta análise foi obtida em medição geodésica em campo durante período de maré baixa de sizígia. Citado em Lessa (2006) e verificado em campo, nas horas de maré cheia a área de praia diminui muito.

Como a variação da faixa de areia do ambiente praial é um vetor natural que não é possível ser controlado, fica claro a necessidade de criar espaços de relaxamento aos turistas nos horários de maré cheia, que normalmente ocorrem próximo à hora do almoço e ao final de tarde. Uma alternativa seria estimular a utilização de infraestruturas pouco utilizada propondo uma revitalização destes espaços. Como exemplo, a área externa do museu, por ser uma edificação já consolidada, poderia ser revitalizada, oferecendo espaço de descanso ao turista. A casa de máquinas também poderia ser relocada para outro espaço, deixando a área que ocupa, perto ao mar e o quiosque náutico, para circulação e permanência do turista.

Por sua vez o parquinho encontra-se em área ambientalmente instável e sugere-se sua relocação para uma área mais plana e acessível. O píer chegada/saída apresenta um fluxo alto de turista. Sua ampliação ofereceria maior conforto durante os horários de chegada e saída da ilha. O mirante da trilha também poderia ser requalificado a fim de torná-lo mais amplo e atrativo ao turista, promovendo o serviço de trilha guiada ofertado pelo complexo.

$\mathrm{O}$ palco de atividades aparece como inconstante devido à baixa frequência de 
usuários, pois é utilizado somente para grupos em apenas duas atividades diárias. Entretanto sua re-qualificação poderia tornar o espaço mais agradável para que o mesmo pudesse ser utilizado como espaço de relaxamento nos períodos de maré cheia. Já a loja de suvenires, localizada em área central e nobre, possui estrutura atrativa. Devido a baixa freqüência de usuários, sugere explorar este tema através de questionários com turistas, verificando in loco as expectativas do turistas frente à aquisição de suvenires do complexo turístico.

O restaurante central e o da segunda praia estão classificados como unidades da paisagem inconstantes devido a sua extensa área. Entretanto, ambas são edificações consolidadas e apresentam boa frequência de usuários, e funcionam como atrativo essencial da ilha. Além disso, o restaurante central possui estrutura permeável e bastante integrada com o espaço natural, sem utilizar cortes ou aterros em sua estrutura construtiva. Isto sugere que o critério de área utilizado nesta metodologia pode não descrever de maneira apropriada a adequação da infraestrutura para a sustentabilidade do turismo. Portanto, entende-se que há necessidade de explorar com maior profundidade os critérios de análise do ambiente social.

\section{CONSIDERAÇÕES FINAIS}

Ao classificar as unidades de paisagem e dimensionar os equipamentos de uso turístico-recreativo da llha de Porto Belo, focando a análise das informações e a discussão dos resultados com base na teoria sistêmica, este estudo pretende contribuir em duas principais frentes: uma frente prática com a geração de subsídios para orientar e aprimorar a gestão do uso turístico-recreativo da IPB; e outra eminentemente metodológica, pela qual a categoria "paisagem" é incorporada na formulação de um ordenamento espacial necessário à sustentabilidade turística, sobretudo, em sua dimensão ambiental. Neste sentido, os resultados obtidos no estudo de Santos e Rejowski (2013) sobre artigos publicados em 20 periódicos científicos brasileiros de turismo entre 1990 e 2012, revelou que não foram encontradas entre as palavras chave mais recorrentes neste universo, os termos unidades de paisagem e sistema de informação geográfica, representativos do presente estudo. Embora não se tenham dados equivalentes de um período mais recente, fica evidente a incipiência desta abordagem entre os pesquisadores do país, voltada para o campo do turismo e da sustentabilidade de destinos.

Dessa forma, a classificação das unidades de paisagem como (constante/transição/inconstante) permitiu uma compreensão tanto da sua organização (estrutura), obtida pelo cruzamento dos aspectos naturais e sociais, como do seu funcionamento (processo), mediante a adequação no dimensionamento dos equipamentos de uso turístico-recreativo em relação à proteção dos aspectos naturais, com base na aplicação da matriz de relacionamento dos cenários natural e social para a definição da estabilidade de unidades de paisagem, gerando a classificação: 
adequado=constante; restrito=transição; e inadequado=inconstante.

Como a metodologia apresenta grande facilidade de incorporar novas variáveis para a análise, uma sugestão para estudos futuros seria incorporar na análise do sistema social os resultados pesquisa de campo frente à percepção do turista em relação ao espaço. Outra possibilidade que poderá ser explorada é a inserção de uma média ponderada para o cruzamento das variáveis, explorando de forma mais efetiva o peso que cada elemento da paisagem tem frente aos bens e serviços oferecidos no complexo turístico-recreativo. Sugere-se ainda para novos estudos, que a definição dos pesos seja ponderada através do método de auxilio à tomada de decisão complexas por meio de multicritérios, o AHP-Analytic Hierarchy Process (Costa, 2002). O AHP é um procedimento compreensivo e racional que auxilia a tomada de decisão que permite analisar várias alternativas e as comparar rapidamente através de uma hierarquia de critérios ponderados por preferências (pesos). Por fim, recomenda-se que questionamentos sobre a percepção do espaço aplicados ao turista e aos gestores da ilha sejam utilizados para converter as preferências, ou julgamentos humanos, em valores numéricos, construindo assim um novo modelo de tomada de decisão mais preciso.

\section{REFERÊNCIAS}

Alister, M. (1982). Tourism: economic, physical, and social impacts. New York: Longman Inc.
Bertalanffy, L.V. (2009). Teoria geral dos sistemas: fundamentos, desenvolvimento e aplicações. 4. ed. Petrópolis: Vozes.

Bertrand, G. (1972). Paisagem e geografia física global - esboço metodológico. Caderno de Ciências da Terra, (13): 01-27. Instituto de Geografia, São Paulo.

Blancas, F. J; González, M.; Lozano-Oyola, M.; Pérez, F. (2010). The assessment of sustainable tourism: application to spanish coastal destinations. Ecological Indicators, 10: 484-492.

Boullón, R. C. (2002). Planejamento do espaço turístico. São Paulo: Edusc.

Bramwell, B. (2015). Theoretical activity in sustainable tourism research. Annals of Tourism Research, 54: 204-218.

Buckley, R. Sustainable tourism: research and reality. (2012) Annals of Tourism Research, 39 (2): 528-546.

Butler, R. (1991). Tourism, environment, and sustainable development. Environmental Conservation, 18 (3): 201-209.

Capra, F. (1992). O Ponto de mutação. São Paulo: Cultrix.

Carvalho, R.G.A.; Decol. F.; Gil, L.F.; Lanzer, R.M. (2016). Um estudo sobre as atividades turísticas em seis ilhas brasileiras. Revista Brasileira de Pesquisa em Turismo. São Paulo, 10(1), pp. 173188, jan./abr.

Cooper, C. (2001). Turismo: princípios e práticas. 2. ed. Porto Alegre: Bookman.

Costa, H.G. (2002). Introdução ao método de análise hierárquica: análise multicritério no auxílio à decisão. Niterói: H.G.C.

Crepani, E.; Medeiros, J. S.; Filho, P. H.; Florenzano, T. G; Duarte, V.; Barbosa, C. C. F. (2001). Sensoriamento remoto e geoprocessamento aplicados ao zoneamento ecológico- 
econômico e ao ordenamento territorial. São José dos Campos: INPE.

Drack, M e Bertalanffy, L.V. (2008). Early system approach. Proceedings of the 2nd Annual Meeting of the ISSS - 2008, Madison, Wisconsin. Disponível em: http://journals.isss.org/index.php/proceedings5 2nd/article/viewFile/1032/322. Aceso el 30/02/2015.

EIA (2008). Estudo de impacto ambiental do EcoResort Ilha de Porto Belo (Porto Belo/SC). Florianópolis: Ilha João da Cunha Participações e Empreendimentos Ltda. Empresa Socioambiental Consultores associados. Volume I.

Figueiró, A.S. (1997). Aplicação do zoneamento ambiental no estudo da paisagem: uma proposta metodológica. Dissertação de mestrado. Universidade Federal de Santa Catarina, Florianópolis.

Forman, R.T.; Gordon, M. (1986). Landscape ecology. New York: John Wiley.

GSTC (2008). The Global Sustainable Tourism Criteria, Partnership for Global Sustainable Tourism Criteria. Disponível em: http://www.sustainabletourismcriteria.org/ Acesso em abril de 2016.

Jiménez, C.C.; Nechar, M.C. (2014). Sosteniendo al turismo o turismo sostenible: reflexiones teóricas. Estudios y Perpectivas en Turismo. v. 23, pp 376-395.Documentos Especiales.

Jovicic, D. Z. (2014). Key issues in the implementation of sustainable tourism. Current Issues in Tourism, 17 (4): 297-302. Disponível em http://dx.doi.org/10.1080/13683500.2013.7973 86. Acesso em abril 2016.

Lessa, B. C. (2006). Proposta de um Método de Análise de Capacidade de Carga da llha de Porto Belo-Ilha São João da Cunha, Município de Porto Belo/SC- Brasil. Dissertação de mestrado. Itajaí: Universidade do Vale do Itajaí.
MORAES, L. N. (2012). Dimensão mercadológica de sustentabilidade do desenvolvimento turístico. In: BENI, M. C. (Organizador) Turismo: Planejamento Estratégico e Capacidade de Gestão. Barueri, SP: Manole.

Mussi, C.S. (2011). Avaliação da sensibilidade ambiental costeira e de risco a elevação média dos oceanos e incidência de ondas de tempestade: um estudo de caso para llha de Santa Catarina. Dissertação de mestrado, Universidade do Vale do Itajaí.

Odum E.P.; Barrett, G. W. (2011). Fundamentos de ecologia. São Paulo: Cengage Learning.

Oliveira, J. P. (1999). Glossário de Turismo e Hotelaria. Turismo Visão \& Ação. Edição Especial.

Oliveira, J.P.; Tricárico, L.T.; Varella, B.G.; Velasquez, G.G. (2016). Arquitetura hoteleira sob a ótica da sustentabilidade e da hospitalidade do espaço: um estudo sobre a aplicação dos conceitos de sustentabilidade e hospitalidade do espaço em projetos de hotéis. Revista Brasileira de Pesquisa em Turismo. São Paulo, 10(1), pp. 189-209, jan./abr.

OMT, Organização Mundial do Turismo. (2003). Guia de desenvolvimento do turismo sustentável. Porto Alegre: Bookmann.

Pearce, D.G. (2016). Modelos de Gestión de Destinos. Estudios y Perpectivas en Turismo, v. 25, no 1, p1-16.

PNUMA- Programa das Nações Unidas para el Medio Ambiente; OMT-Organización Mundial del Turismo. (2006). Por um turismo más sostenible: guia para responsables políticos. España, Disponível em .<http://www.unep.fr/shared/publications/pdf/ DTIx0884xPA-TourismPolicyES.pdf>. Consulta em maio de 2013.

Ribeiro,H.; Stigliano,B. V. (2010). Desenvolvimento turístico e sustentabilidade ambiental. In: Philippi JR, A.; Ruschmann, D. 
M.(Org). Gestão ambiental e sustentabilidade no turismo. Barueri: Manole. pp 63-82.

Rosa, F.S.; Silva, L.C. (2017) Sustentabilidade ambiental em hotéis: análise de artigos científicos publicados em periódicos internacionais no período de 1996 a 2016. Revista Brasileira de Pesquisa em Turismo. São Paulo, 11(1), pp. 39-60, jan./abr.

Ruhanen, L. (2008). Progressing the sustainability debate: a knowledge management approach to sustainable tourism planning. Current Issues in Tourism. 11 (5)

Ruschmann, D. V. de M. (2009). Planejamento sustentável do turismo. 14a. Ed. Papirus, Campinas.

Ruschmann, D.Van de M.; Rosa, R. G.; Weidgenant, P. J. Z. (2008). Sustentabilidade como estratégia de desenvolvimento: Ilha de Porto Belo / SC. In: JR PHILIPPI, A.; RUSCHMANN, D.. (Org.). Gestão ambiental e sustentabilidade no turismo. Manole, Barueri, pp 811-842 .

Sancho, A. (2001). Introdução ao turismo. Trad. Dolores Martin R. Corner. Roca, São Paulo.

Santana, N. A. de. (1998). A produção do espaço urbano e os loteamentos na cidade de Joinville (SC) - 1949/1996. Dissertação de mestrado. Universidade Federal de Santa Catarina, Florianópolis.

Santos, M. (1992). Espaço \& Método. 3. ed. Nobel, São Paulo.

Santos, T.M.; Melo, R.S.; Brito, A.S. (2013). Turismo e desenvolvimento sustentável na Praia de Atalaia, Luís Correia, Piauí, Brasil. Turydes, Revista de Investigación em turismo e desarrollo local: 16, (15): diciembre.

Santos, G. E. de O.; Rejowski, M. (2013). Comunicação científica em turismo no Brasil: Análises descritivas de periódicos nacionais entre 1990 e 2012. Revista Brasileira de Pesquisa em Turismo. São Paulo, 7(1), pp. 149-167, jan./abr.
Silva, N.C.; Cândido, G.A. (2016). Sistema de indicadores de sustentabilidade do desenvolvimento do turismo: um estudo de caso do município de Areia - PB. Revista Brasileira de Pesquisa em Turismo. São Paulo, 10(3), pp 475496, set./dez.

Torres-Delgado; A.; Palomeque, F. L. (2012). The growth and spread of the concept of sustainable tourism: The contribution of institutional initiatives to tourism policy. Tourism Management Perspectives 4: 1-10

Tres, D. R.; Reis, A.; Schlindwein, S.L. (2011). A construção de cenários da relação homem/natureza sob uma perspectiva sistêmica para o estudo da paisagem em fazendas produtoras de madeira no Planalto Norte Catarinense. Ambiente \& Sociedade, 14: (1), jan./jun: 151-173

Vieira, R. (1999). Interpretação integrada da paisagem para identificar a qualidade ambiental na sub-bacia do Ribeirão Garcia - Blumenau/SC. Dissertação de mestrado, Universidade Federal de Santa Catarina, Florianópolis.

Willians, P. W. ; Ponsford I. F.. (2009). Confronting tourism's environmental paradox: Transitioning for sustainable tourism. Futures. 41 (6): 396-404

WTO - World Tourism Organization (2005). Making tourism more sustainable - a guide for policy makers. Madrid: WTO.

WTO - World Tourism Organization (2004). Indicators of sustainable development for tourism destinations. A guidebook". Madrid: WTO.

WTO - World Tourism Organization (2010). Tourism quality standards and systems and their relationship with sustainability and tourism law The Experience of the Americas. Madrid: WTO.

WTO - World Tourism Organization (2011). Handbook on tourism product development. Madrid: WTO. 
WTO - World Tourism Organization (2013a). Challenges and opportunities for tourism development in small island developing states. Madrid: WTO.

Dados dos autores

\section{Rafaela Vieira}

Universidade Regional de Blumenau (FURB),

WTO - World Tourism Organization (2013b).

Blumenau, SC, Brasil. E-mail:

Sustainable tourism governance and arquitetura.rafaela@gmail.com

management in coastal areas of Africa. Madrid: WTO.

WTO - World Tourism Organization (2007). A

\section{Carolina Mussi}

Universidade do Vale do Itajaí (UNIVALI). Balneário

Camboriú, SC, Brasil.E-mail: csmussi@gmail.com

practical guide to tourism destination
management. Madrid: WTO.

Yázigi, E. (2003). Civilização urbana: Paulo Pires

Universidade do Vale do Itajaí (UNIVALI). Balneário Camboriú, SC, Brasil. E-mail: pires@univali.br planejamento e turismo. São Paulo: Contexto, 